\title{
Autoantibodies, C-reactive protein, erythrocyte sedimentation rate and serum cytokine profiling in monitoring of early treatment
}

\author{
EDYTA BRZUSTEWICZ ${ }^{1}$, IZABELLA HENC ${ }^{l}$, AGNIESZKA DACA ${ }^{l}$, MARIA SZARECKA ${ }^{2}$, \\ MALGORZATA SOCHOCKA-BYKOWSKA ${ }^{2}$, JACEK WITKOWSKI ${ }^{3}, E W A B R Y L^{l}$ \\ ${ }^{1}$ Department of Pathology and Experimental Rheumatology, Medical University of Gdansk, Poland \\ ${ }^{2}$ Voivodal Rheumatology Hospital, Sopot, Poland \\ ${ }^{3}$ Chair and Department of Pathophysiology, Medical University of Gdańsk, Poland
}

\begin{abstract}
Introduction: Currently used clinical scale and laboratory markers to monitor patients with early rheumatoid arthritis (RA) seem to be not sufficient. It has been demonstrated that disease-related cytokines may be elevated very early in RA development and cytokines are considered as the biomarkers potentially useful for $R A$ monitoring.

Material and methods: The group of patients with undifferentiated arthritis (UA) developing $R A$ $(U A \rightarrow R A)$ was identified from a total of 121 people with arthralgia. $U A \rightarrow R A(n=16)$ and healthy control $(n=16)$ subjects underwent clinical and laboratory evaluation, including acute phase reactants (APRs) and autoantibodies. Cytokines IFN- $\gamma, I L-10, T N F, I L-17 A, I L-6, I L-1 \beta, I L-2$ in sera were assayed using flow cytometric bead array test.

Results: $34.5 \%$ of patients with UA developed RA. DAS28 reduced as early as 3 months after initiation of treatment. No DAS28 difference between groups of autoantibody (RF, anti-CCP, ANA-HEp-2) -positive and-negative patients was observed, however, comparing groups of anti-CCP and RF-double negative and-double positive patients, the trend of sooner clinical improvement was visible in the second abovementioned group. After the treatment introduction, the ESR level reduced significantly, while CRP level reduction was not significant. Serum cytokine levels of IL-10, IL-6 and IL-17A reduced after 6 months since introduction of treatment. The positive correlations between ESR, CRP and specific cytokine levels were observed.

Conclusions: The autoantibody and APR profile is poorly connected with the RA course. The serum cytokine profile change in the course of $R A$ and may be potentially used for optimization of $R A$ monitoring.
\end{abstract}

Key words: rheumatoid arthritis, cytokines, biomarkers, undifferentiated arthritis, disease monitoring.

(Cent Eur J Immunol 2017; 42 (3): 259-268)

\section{Introduction}

Rheumatoid arthritis (RA) is a chronic autoimmune disease leading to severe disability and premature mortality [1]. Although the aetiology of RA remains unclear, over the past years the significant progress in RA processes understanding has been done [2-4]. Measurement of disease activity became a crucial component of RA management [5]. Due to high degree of heterogeneity of RA, the assessment of disease activity requires a number of subjective and objective criteria of disease supplemented by laboratory parameters [6]. Precise disease assessment and a prediction of outcomes in reliable way would provide means for optimization of care [7]. The disease activity score (DAS) is a tool used to monitor RA activity. It combines swollen and tender joints, acute phase reactants (APR): $\mathrm{C}$-reactive protein (CRP) or erythrocyte sedimentation rate (ESR) and a patient-reported measure of general health using Visual Analog Scale (VAS) [8]. Autoantibodies such as rheumatoid factor (RF) and antibodies to citrullinated

Correspondence: Edyta Brzustewicz, Department of Pathology and Experimental Rheumatology, Medical University of Gdansk, Debinki 7 , 80-211 Gdansk, Poland, e-mail: edytabrzustewicz@gumed.edu.pl Submitted: 13.09.2016; Accepted: 2.02.2017 
protein antigens (ACPAs), the most common commercially available as anti-cyclic citrullinated peptide antibodies (anti-CCP), are used most often to confirm RA diagnosis, on occasion may be used to predict a prognosis or an organ involvement $[9,10]$. Another serological marker, such as serum antinuclear antibodies (ANA) has been demonstrated to prevail in RA and they are extensively explored as laboratory tool for diagnosis and follow-up of systemic autoimmune rheumatic diseases (SARDs) $[11,12]$. In the last few years, there has been demonstrated that laboratory panel used in RA monitoring may be further elucidated by a cytokine evaluation $[13,14]$. Multiple studies have demonstrated that disease-related cytokines may be elevated even in healthy, asymptomatic blood donors, who have later developed RA and cytokines are considered as the potential RA biomarkers [13-15].

There is, as yet, insufficient evidence that any marker, in isolation or in combination can sufficiently predict disease outcome and assess early RA activity. Therefore, we undertook a prospective longitudinal study to assess the relative usefulness of available markers as prognostic and monitoring tool, and we completed it with the serum multi-cytokine evaluation.

\section{Material and methods}

\section{Study group}

The study group constituted of 16 patients with undifferentiated arthritis (UA), who developed RA. That group was identified from a total of 121 people with suspected UA identified at Regional Hospital for Rheumatic Diseases in Sopot, Poland. All subjects underwent a wide range of laboratory tests, including: acute phase reactants (ESR, CRP), serological markers - (RF [immunoturbidymetric method], anti-CCP [electrochemiluminescence method], antithyroglobulin antibodies (anti-TG) [electrochemiluminescence method], ANA-HEp2 [immunofluorescence method]), complete blood count (CBC), alanine aminotransferase (ALT), fasting blood glucose, aspartate aminotransferase (AST) and creatinine, serological markers of hepatitis $\mathrm{B}$, hepatitis $\mathrm{C}$ and human immunodeficiency virus (HIV), and general urine test. Clinical assessment of their status included: tender joint count (TJC), swollen joint count (SJC), American College of Rheumatology (ACR) tender score, ACR swollen score, DAS28-CRP and VAS. Of the 121 initially identified, 58 patients with suspected UA (mean age $43.5 \pm 11.9$ [mean $\pm \mathrm{SD}$ ] years) met following criteria:

1) had a minimum of one peripheral joint inflammation lasting from 2 to 4 months;

2) were not treated with disease modifying anti-rheumatic drugs (DMARDs), biological treatment (bDMARDs) nor steroids;
3) did not fulfil any of the American College of Rheumatology/European League Against Rheumatism Collaborative Initiative (ACR/EULAR) classification criteria for any specific rheumatic disease at the time of enrolment; thus, they were diagnosed as UA.

The final diagnoses and the introduction of DMARD treatment (sulfasalazine [SSZ], methotrexate [MTX] or Arechin) were made during 6 months since first visit.

From total of 58 UA patients, 20 were classified as having rheumatoid arthritis $(\mathrm{UA} \rightarrow \mathrm{RA})$ and 16 of them completed the whole study procedure, participating in another two follow-up visits which occurred over three and six months since the final diagnosis. These patients constituted the study group.

The control group consisted of 16 clinically healthy volunteers, without any symptoms of joint inflammation, with no autoimmune or chronic inflammatory diseases in personal or family history. Healthy volunteers were not blood donors and were recruited among Pomeranians, Poland. The control individuals were examined by the same rheumatologists and they had undergone the same range of laboratory tests as the patients. The demographical and clinical characteristics of UA $\rightarrow$ RA and healthy volunteers groups are presented in Table 1.

The study was approved by the Local Independent Committee for Ethics in Scientific Research at the Medical University of Gdansk and the written consent was obtained from all patients and controls.

\section{Measurement of cytokines}

Cytokines in sera were assayed using flow cytometric bead array BD ${ }^{\text {TM }}$ CBA Flex Sets (BD Bioscience, USA). Blood sera from $\mathrm{UA} \rightarrow \mathrm{RA}$ patients and healthy subjects were collected and centrifuged at $4000 \mathrm{rpm}$ for $5 \mathrm{~min}$ utes. These serum samples were kept frozen at $-80^{\circ} \mathrm{C}$ until further processing for the simultaneous quantification of 7 cytokines: interferon- $\gamma$ (IFN- $\gamma$ ), interleukin-10 (IL-10), tumour necrosis factor (TNF), interleukin-17A (IL-17A), interleukin-6 (IL-6), interleukin-1 $\beta$ (IL-1 $\beta$ ), interleukin-2 (IL-2). The assay was performed according to the manufacturer's instructions. Briefly, antibody-coupled beads specific for single cytokines were mixed and incubated with $50 \mu \mathrm{l}$ of sera. Then they were incubated with mixture of detection antibodies conjugated to reporter molecules (phycoerithrin - PE). Following incubation and subsequent washing, the samples were acquired using a flow cytometer (BD FACS Array, BD Biosciences, USA).

\section{Data analysis}

The Kolmogorov-Smirnov test revealed no-normal distribution of the parameters. The differences between cytokine and acute phase reactant concentrations before and after diagnosis and introduction of treatment were calculated by the Wilcoxon test. The significance of differences 
Table 1. Demographical and clinical characteristic of groups and treatment used in UA $\rightarrow$ RA group. Differences in laboratory parameters between $\mathrm{UA} \rightarrow \mathrm{RA}$ and healthy control groups were considered to be statistically significant at $p<0.05$

\begin{tabular}{|c|c|c|c|}
\hline Parameter & $\mathbf{U A} \rightarrow \mathbf{R A}$ & Control group & $p$ \\
\hline individuals, $\mathrm{N}$ & 16 & 16 & \\
\hline ages, years, & $\begin{array}{c}46.5 \\
(18-61)\end{array}$ & $\begin{array}{c}37.3 \\
(26-49)\end{array}$ & \\
\hline female, $\mathrm{N}$ & 14 & 16 & \\
\hline
\end{tabular}

\begin{tabular}{lcc}
14 & 16 \\
\hline treatment, $\mathrm{N}$ & MTX, 5 \\
& MTX, NSAID, 3 \\
SSZ, 2 & SSZ, MIX, 2
\end{tabular}

SSZ, MTX, 2

NSAID, Arechin, 1

NSAID, Arechin, Metypred, 1

NSAID, 2

\begin{tabular}{|c|c|c|c|c|c|}
\hline & Visit 1 & Visit 2 & Visit 3 & & \\
\hline DAS28 & $\begin{array}{c}4.66 \\
(3.54-6.26)\end{array}$ & $\begin{array}{c}3.95 \\
(1.34-5.36)\end{array}$ & $\begin{array}{c}2.93 \\
(1.23-4.65)\end{array}$ & & \\
\hline WBC, G/1 & $7.2(4.2-12.3)$ & $6.3(4.3-10.8)$ & $6.0(4.6-9.3)$ & $6.2(3.6-11.1)$ & NS \\
\hline $\mathrm{RBC}, \mathrm{T} / 1$ & $4.5(4.2-5.0)$ & $4.5(3.8-5.1)$ & $4.4(3.9-4.8)$ & $4.5(4.0-5.3)$ & NS \\
\hline $\mathrm{Hgb}, \mathrm{g} / \mathrm{dl}$ & $13.0(10.9-14.1)$ & $13.3(11.6-14.5)$ & $13.4(10.5-14.8)$ & 13.5 (11.5-15) & NS \\
\hline$\% \mathrm{Hct}$ & $38.9(34.5-42)$ & $39.4(35.0-41.8)$ & $39.4(33.0-42.5)$ & $39.5(34-43.3)$ & NS \\
\hline $\mathrm{MCV}, \mathrm{fl}$ & $87.1(77.8-94.1)$ & $88.6(81.9-92.7)$ & $89.5(80.5-92.6)$ & $86.4(76.7-94.5)$ & NS \\
\hline $\mathrm{MCH}, \mathrm{pg}$ & $29.4(24.8-31.8)$ & $29.5(26.7-32.7)$ & $30.2(25.6-32.1)$ & $29.7(25.3-33.2)$ & NS \\
\hline $\mathrm{MCHC}, \mathrm{g} / \mathrm{dl}$ & $33.6(31.6-34.9)$ & $33.5(32.5-35.4)$ & $34.2(31.8-35.4)$ & $34.15(33-35.1)$ & NS \\
\hline$\%$ RDW & $13.3(12.6-23.2)$ & $14.3(12.5-16.3)$ & $13.7(12.9-17.0)$ & $12.8(11.8-15.7)$ & NS \\
\hline PLT, G/1 & $287(174-501)$ & 260 (176-399) & $271(230-424.0)$ & 283 (221-344) & NS \\
\hline MPV, fl & $10.6(10.1-12.4)$ & $10.7(9.8-12.0)$ & $10.7(9.5-12.4)$ & $10.4(9.5-12.5)$ & NS \\
\hline $\begin{array}{l}\text { neutrophils, G/l } \\
\%\end{array}$ & $\begin{array}{c}5.0(2.1-8.8) \\
66.7(45.4-71.4)\end{array}$ & $\begin{array}{c}3.7(2.1-6.5) \\
58.7(49.2-74.0)\end{array}$ & $\begin{array}{c}3.7(2.7-6.2) \\
60.6(49.9-67.1)\end{array}$ & $\begin{array}{c}3.5(1.5-8.5) \\
57.0(36.6-76.5)\end{array}$ & NS \\
\hline $\begin{array}{l}\text { lymphocytes, G/l } \\
\%\end{array}$ & $\begin{array}{c}1.7(1.1-2.9) \\
23.1(17.2-43)\end{array}$ & $\begin{array}{c}1.8(1.3-3.5) \\
31.1(19.8-42.1)\end{array}$ & $\begin{array}{c}1.8(1.1-2.8) \\
29.4(23.2-38.2)\end{array}$ & $\begin{array}{c}1.9(0.7-3.8) \\
30.9(15-47.8)\end{array}$ & NS \\
\hline $\begin{array}{l}\text { monocytes, } \mathrm{G} / 1 \\
\%\end{array}$ & $\begin{array}{c}0.5(0.3-1.1) \\
7.7(4.9-10.1)\end{array}$ & $\begin{array}{c}0.5(0.3-1.0) \\
8.3(5.6-13.2)\end{array}$ & $\begin{array}{c}0.5(0.3-1.0) \\
8.2(5.5-11.9)\end{array}$ & $\begin{array}{c}0.5(0.1-0.8) \\
7.1(2.9-11.6)\end{array}$ & NS \\
\hline $\begin{array}{l}\text { eosinophiles, G/1 } \\
\%\end{array}$ & $\begin{array}{c}0.15(0.04-0.38) \\
2.6(0.6-4.3)\end{array}$ & $\begin{array}{c}0.13(0.03-0.33) \\
1.8(0.5-5.7)\end{array}$ & $\begin{array}{c}0.09(0.02-0.33) \\
1.7(0.4-6.5)\end{array}$ & $\begin{array}{c}0.12(0.03-0.30) \\
2.3(0.4-5.2)\end{array}$ & NS \\
\hline $\begin{array}{l}\text { basophiles, G/1 } \\
\%\end{array}$ & $\begin{array}{c}0.02(0.01-0.07) \\
0.25(0.2-1.00)\end{array}$ & $\begin{array}{c}0.02(0.00-0.06) \\
0.3(0.0-0.7)\end{array}$ & $\begin{array}{c}0.02(0.01-0.05) \\
0.4(0.1-0.6)\end{array}$ & $\begin{array}{c}0.02(0.01-0.05) \\
0.25(0.1-0.7)\end{array}$ & NS \\
\hline $\mathrm{ALT}, \mathrm{U} / \mathrm{l}$ & $18.5(8-32)$ & $23(10-53)$ & $19(9-35)$ & $15(8-91)$ & NS \\
\hline AST, U/1 & $20.5(11-30)$ & $20(11-36)$ & $20(10-31)$ & $19(11-43)$ & NS \\
\hline HbsAg, N & 0 & 0 & 0 & 0 & NS \\
\hline anti-HCV, N & 0 & 0 & 0 & 0 & NS \\
\hline ESR, N (mm/h) & $22(5-49)$ & $12(3-33)$ & $15(5-49)$ & $15.5(2-41)$ & NS \\
\hline CRP, g/l & $1.7(0.5-17.6)$ & $1.4(<0.3-9.4)$ & $3.1(<0.3-8.9)$ & $1.5(<0.3-15.1)$ & NS \\
\hline creatinine, $\mathrm{mg} / \mathrm{dl}$ & $0.7(0.6-0.97)$ & $0.8(0.5-1.1)$ & $0.74(0.6-1.0)$ & $0.81(0.67-0.9)$ & NS \\
\hline eGFR, $\mathrm{ml} / \mathrm{min}$ & $>60$ & $>60$ & $>60$ & $>60$ & NS \\
\hline $\begin{array}{l}\text { anti-HIV, } \\
\mathrm{N} \text { (positive) }\end{array}$ & 0 & & & 0 & NS \\
\hline
\end{tabular}

Data are presented as median (min.-max.) or number of individuals.

ACR - American College of Rheumatology; ALT - alanine aminotransferase; Anti- HCV - antibodies against hepatitis C; AST - aspartate aminotransferase $C R P-C$-reactive protein; DAS - Disease Activity Score; ESR - erythrocyte sedimentation rate; MDRD-eGFR - Modification of Diet in Renal Disease formula of estimated glomerular filtration rate; HbsAg - surface antigen of hepatitis B; Hct - hematocrit; Hgb - hemoglobin; HIV - human immunodeficiency virus MCH - mean corpuscular haemoglobin; MCHC - mean corpuscular haemoglobin concentration; MCV - mean corpuscular volume; MPV - mean platele volume; MTX - methotrexate; NS - not statistically significant, NSAID - non-steroid anti-inflammatory drugs; PLT - platelets; RDW - red cell distribution width; RBC - red blood cells; SJC - swollen joint count; SSZ - sulfasalazine; TJC - tender joint count; WBC - white blood cells 

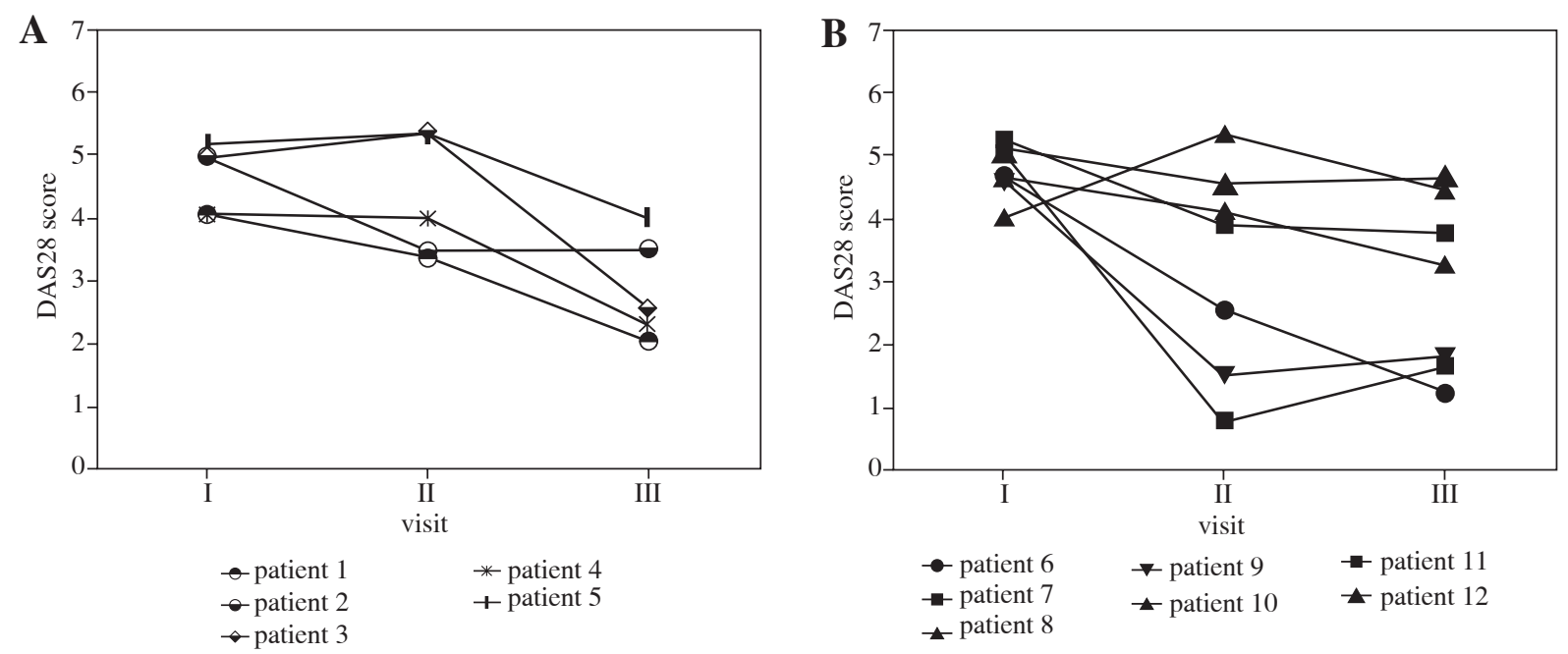

Fig. 1. Visit-to-visit changes of DAS28 in groups of anti-CCP- and RF-positive (A) and -negative patients (B). Each symbol and line represents the DAS28 score of one UA $\rightarrow$ RA patient

between cytokine levels in groups of $\mathrm{UA} \rightarrow \mathrm{RA}$ patients and healthy controls were calculated by $U$ Mann-Whitney test. The correlations between the concentrations of each parameter were tested using Spearman correlation. Differences for all were considered to be significant at $p<0.05$. GraphPad Prism version 6.00 for Windows (GraphPad Software, La Jolla California USA, www.graphpad.com) and Statistica ${ }^{\mathrm{TM}} 10$ (StatSoft analysing software, Poland) were used for all statistical analyses and plots.

\section{Results}

\section{Demographic and clinical data}

In the group of patients with arthralgia $(n=121)$, $47.9 \%(n=58)$ developed UA and $16.5 \%(n=20)$ were diagnosed as RA, during 6 months from the first rheumatology visit. Thus, patients developing RA constituted $34.5 \%$ of patients with UA. Characteristic of study group (16 patients developing RA and participating in the follow-up studies after 3 and 6 months since diagnosis) is showed in Table 1. The ratio of female to male in the $\mathrm{UA} \rightarrow \mathrm{RA}$ group was $14: 2$. Since diagnose as RA, the patients had introduced steroids, DMARD or non-steroid anti-inflammatory drugs (NSAID). The DAS28 decreased significantly after 3 and 6 months since diagnosis and introduction of treatment (second and third visit, respectively; Fig. 2). Considering DAS2 $8<2.6$ as cut point of clinical remission and DAS28 $\leq 3.2$ as low disease activity and DAS28 $>3.2$ high disease activity [16] (1), all patients had high disease activity in the first visit, in the second visit 4 of them were in the remission, while 8 patients were in a remission at the third visit. The median value of laboratory tests such as complete blood counts $(\mathrm{CBC})$, hepatic and renal laboratory profiles or CRP in both groups were within the normal ranges and they did not differ statistically significantly. However, the first $U A \rightarrow$ RA visit characterized slightly higher median number of WBC and lower median values of Hct and Hgb in comparison to the healthy group. The virology status (HIV, HBV, HCV) was negative in both groups.

\section{Autoantibody profile in prediction of disease progression}

Baseline autoantibody evaluation of patients was done at the time of entry, 6 to 12 months before established diagnosis.

We did not observed any DAS28 difference between groups of RF-positive, anti-CCP- positive or ANA-HEp-2positive patients and respective seronegative patients within any visit. However, comparing groups of anti-CCP and RF-double negative and anti-CCP and RF-double positive, the trend (no statistically significant) of sooner clinical improvement was visible in the second above- mentioned group (Fig. 1).

Regarding 4 patients being in the remission during the second visit (after 3 months since diagnosis and introduction of treatment), 3 of them were anti-CCP and RF positive and 1 patient was anti-CCP positive. In the group of 8 patients being in remission in the third visit ( 6 months since the diagnosis and introduction of treatment), 3 of them had positive results of both RF and anti-CCP, 3 patients were RF- and- anti-CCP-negative and 2 patients had positive results of anti-CCP.

\section{The serum cytokine levels in patients and controls}

The statistically higher serum cytokine levels in $\mathrm{UA} \rightarrow \mathrm{RA}$ patients than healthy controls were noted on 
Table 2. Serum cytokine concentrations in UA $\rightarrow$ RA and healthy control groups. Data are presented as median [min.max.] (pg/ml); statistical significance of differences of cytokine concentrations between healthy controls and UA $\rightarrow$ RA patients were calculated by U-Mann Whitney test. Differences were considered to be statistically significant at $p<0.05$

\begin{tabular}{|c|c|c|c|c|}
\hline \multirow[t]{2}{*}{ Visit } & \multirow[t]{2}{*}{ Serum cytokine levels } & UA $\rightarrow$ RA patients & \multirow[t]{2}{*}{ Control group } & \multirow[t]{2}{*}{$p$} \\
\hline & & Median (min.-max.), pg/ml & & \\
\hline I & \multirow[t]{3}{*}{ IFN- $\gamma$} & $1.1(0.8-12.4)$ & $1.0(0.7-1.2)$ & $<0.05$ \\
\hline II & & $1.1(0.5-6.9)$ & & 0.08 \\
\hline III & & $0.9(0.8-2.6)$ & & 0.79 \\
\hline I & \multirow[t]{3}{*}{ IL-2 } & $2.9(2.4-17)$ & $2.5(2.1-4.1)$ & $<0.05$ \\
\hline II & & $2.9(2.4-17.1)$ & & $<0.05$ \\
\hline III & & $2.4(1.9-26.2)$ & & 0.36 \\
\hline I & \multirow[t]{3}{*}{ IL-6 } & $8.0(1.9-37)$ & $3.7(1.8-6.1)$ & $<0.05$ \\
\hline II & & $4.5(1.9-29.1)$ & & $<0.05$ \\
\hline III & & $2.7(1.7-18.0)$ & & 0.72 \\
\hline I & \multirow[t]{3}{*}{ IL-10 } & $3.3(1.6-21.8)$ & $2.7(1.4-4.1)$ & $<0.05$ \\
\hline II & & $3.1(1.4-21.7)$ & & $<0.05$ \\
\hline III & & $2.1(1.4-13.6)$ & & 0.49 \\
\hline I & \multirow[t]{3}{*}{ IL-17A } & $15.9(7.8-139.6)$ & $14.6(4.2-15.7)$ & $<0.05$ \\
\hline II & & $15.8(8.5-84.5)$ & & $<0.05$ \\
\hline III & & $7.2(3.4-112.9)$ & & 0.36 \\
\hline I & \multirow[t]{3}{*}{ IL- $1 \beta$} & $2.6(1.9-17.1)$ & $2.4(1.3-3.0)$ & 0.11 \\
\hline II & & $2.6(1.8-21.9)$ & & 0.13 \\
\hline III & & $2.2(1.4-31-7)$ & & 1.0 \\
\hline I & \multirow[t]{3}{*}{ TNF } & $2.9(1.2-37.6)$ & $2.8(1.6-3.6)$ & 0.22 \\
\hline II & & $3.5(1.8-21.3)$ & & $<0.05$ \\
\hline III & & $2.8(1.3-42.9)$ & & 0.81 \\
\hline
\end{tabular}

$\mathrm{UA} \rightarrow \mathrm{RA}$ patients' first and second visit, while at the third visit, after 6 months from diagnosis and introduction of treatment, no statistically significant differences were observed (Table 2).

\section{Inflammatory markers and cytokine profile in the course of disease}

We observed statistically significant reduction of ESR after 3 and 6 months since the introduction of treatment (ESR exceeded normal range: 11/16 in first visit, 6/16 in second visit, 7/16 in third visit) while CRP level reduction was slight, no statistically significant (CRP exceeded normal range: $3 / 16$ in first visit, $3 / 16$ in second visit, $1 / 16$ in third visit). There was no significant correlation between the ESR and hematocrit (Hct) values. Serum cytokine profile changed after 6 months since diagnosis and introduction of treatment. We noticed statistically significant reduction of IL-10, IL-6 and IL-17A between first visit and third visit. No differences were observed for second visit, 3 months of treatment were not sufficient for serum cytokine reduction. The visit-to-visit change of DAS28, APR and cytokine concentrations with $p$-values for that statistically significant are shown in Fig. 2.

\section{Correlation of cytokines, autoantibodies, inflammatory reactants and disease activity scores}

To assess the value of clinical and biological markers in UA progressing to RA we checked the correlation between clinical activities DAS28, acute phase reactants, autoantibody and cytokine levels (Table 3).

No correlation of DAS28 and any parameter were observed for the first visit. The third visit characterized positive correlation of DAS28 with CRP $(r=0.532, p<0.05)$, and IL-6 $(r=0.727, p<0.05)$.

Regarding inflammatory markers, we noted positive correlation between ESR and CRP in each visit. The positive correlations between ESR and IL-1 $\beta$ ( $r=0.579$, 

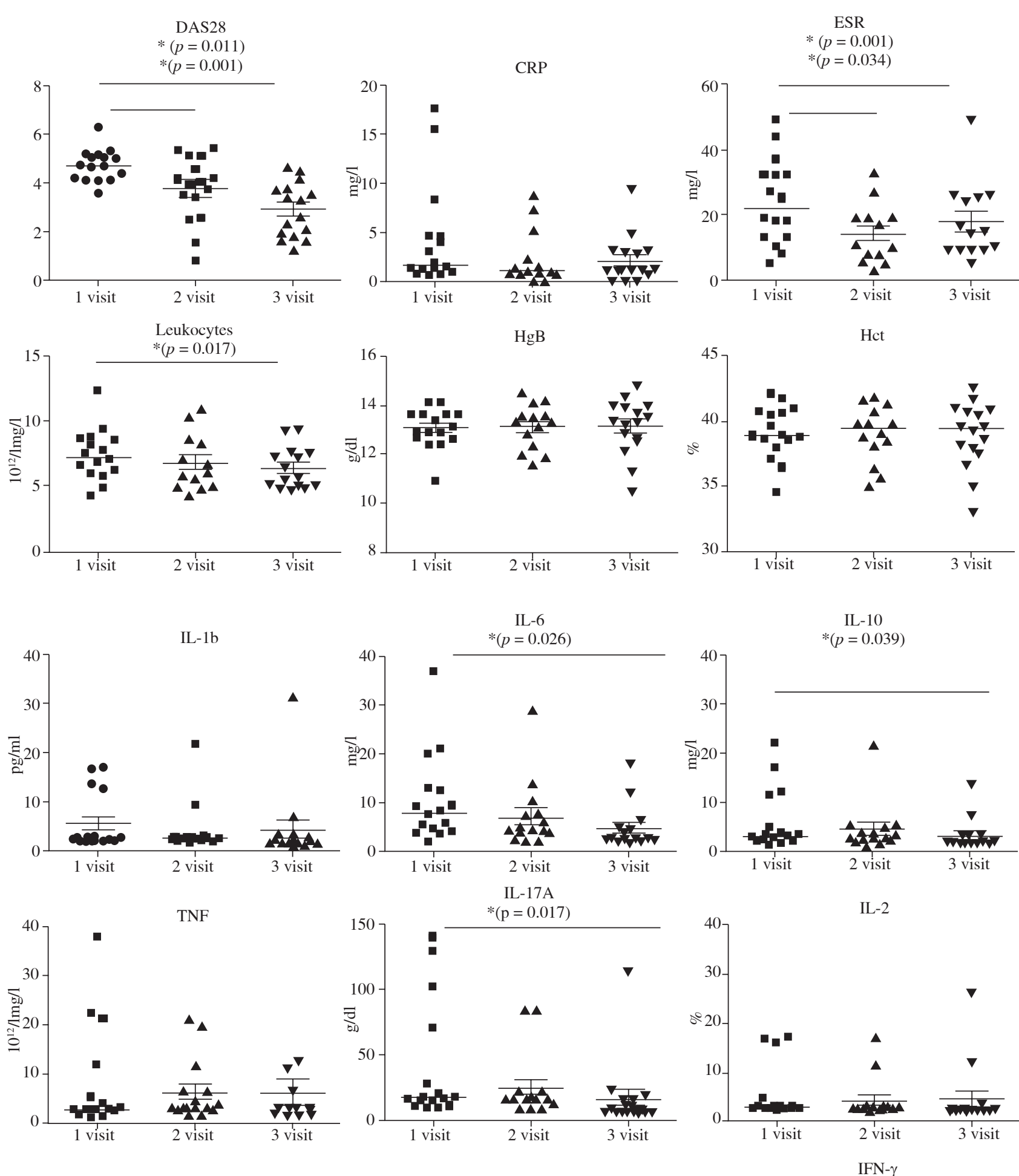

Fig. 2. Visit-to-visit changes of DAS28, serum inflammatory parameters (upper panel) and cytokine concentrations (lower panel). Each dot represents a result obtained for a single patient and medians are represented as horizontal lines

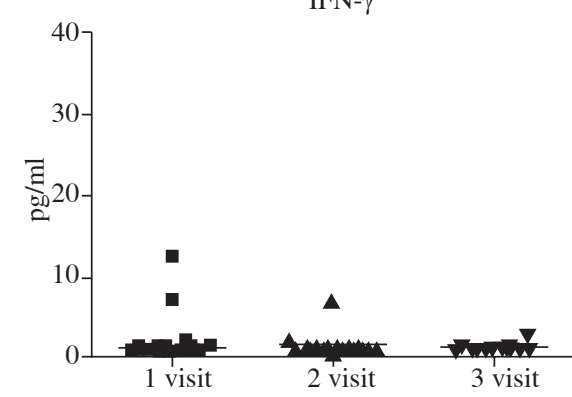


$p<0.05)$ as well as CRP and IL-1 $\beta(r=0.642, p<0.05)$ were observed in the second visit. In the third visit, there was a positive correlation between ESR and IL-6 $(r=$ $0.548, p<0.05)$.

We observed multiple correlations between serum cytokine levels. However, only positive correlation between IL-6 and IL-10 was observed during each visit ( $r=0.826$, $0.829,0.759, p<0.05$ respectively). The positive correlation between IL-6 and IL-17A was noted in first and second visit $(r=0.824,0.774, p<0.05)$.

The autoantibody profile performed after patients were included into UA cohort, did not correlate with any inflammatory and cytokine parameters at the first visit.

\section{Discussion}

In the clinical practice, patients with UA are those patients with the potential for development of persistent inflammatory arthritis, including RA, but in whom a recognized clinical pattern does not exist [17]. The proportion of patients with UA developing RA within 1 year, according different data varied from $6 \%$ to $55 \%[17,18]$. Our study performed according to the 2010 ACR/EULAR criteria for rheumatoid arthritis in the Polish Pomeranian population showed, that $34.5 \%$ of patients with UA developed RA.

Successful management of RA depends upon control of disease exacerbation use of DMARDs, NSAIDS and corticosteroids. Several studies have showed a beneficial effect of the early treatment of RA to achieve better results $[17,19,20]$. However, in the clinical practice, an estimation of disease activity poses essential point in a planning of therapeutic strategy- its introduction and optimization. It has been showed that during DMARDs treatment, a joint destruction may continue to progress, despite both improvement in clinical parameters and persistent reduction of ESR [21]. Therefore, it is vital to identify the parameters that can accurately indicate disease activity and predict progression of disease over time. In our study we used common clinical and laboratory parameters for monitoring of RA activity and we completed them with circulating cytokines as new potential biomarkers. Selected range of biomarkers are involved in systemic inflammation and autoimmune processes, leading to synovial hyperplasia with inflammatory cell infiltration, angiogenesis and cartilage erosion [22].

Our study documents the clinical and health status of UA patients progressing to RA. The routine laboratory measures indicated strong similarities of $U A \rightarrow R A$ to healthy individuals. That lacks of significant differences in basic laboratory profile along with high DAS28 values suggest the necessity of considering potential application of other parameters in early RA diagnosis. In our study we used DAS28 based on CRP. We observed that the introduction of treatment led to significant reduction of DAS28, one-half of patients received remission after
6 months since diagnosis and introduction of treatment. It stays in agreement that DAS28 is a useful tool assessing a disease activity [7, 8]. However, DAS28 correlated only with CRP and IL-6 levels in the third visit. Available data suggest significant positive correlation of DAS28 with CRP, IL-6, TNF and negative correlation with IL-10 in patients with already diagnosed RA [23]. This discrepancy may be dependent on the different patient cohort, in our study the patients were examined at the stage of UA, and some of them developed RA within 3-6 months after the studies were performed.

We checked if the autoantibody profile is connected with the disease course. Our analysis did not confirm that the patients positive to anti-CCP or RF differ in disease course or a response to treatment within 6 months of treatment. However, the more aggressive treatment introduced in the group of patients with positive anti-CCP and RF results comparing to the treatment applied in group of anti-CCP and RF-negative patients generally resulted in sooner clinical improvement in the first above- mentioned group. The study of Vittecoq et al. revealed the association of high level of RF with the presence of aggressive disease in RA during the longer observation [24]. Rantapää-Dahlqvist et al. showed that anti-CCP positive results can predate the onset of symptoms and they can be used as markers of the progression and prognosis of the disease [25].

The limited data concerning ANA-HEp-2 profile of RA patients suggest that those antibodies can be used to predict the development of autoimmune rheumatic disease [9, $12,26,27]$. In our study we did not find any difference in DAS28 score and DAS28 reduction between ANA-HEp2 positive and negative patients. However, the positive correlation of ANA-HEp-2 initial titre and DAS28 in second visit was observed, which suggests more severe course of disease among ANA positive patients.

We supplemented current study with the circulating cytokine profiling. Cytokines are commonly considered as biomarkers of RA and tool for RA monitoring [28-33]. We demonstrated that cytokine deregulation is initialized at a very early UA stage, before fulfilling all RA classification diagnostic criteria and that the treatment introduction attenuates it. In the light of well documented impact of medication on cytokine milieu, in the current study the cytokine rebalance in time should be consider together with an impact of the medication implied. We find correlations between measured cytokines, which was a confirmation of previous reports [28]. However, beside the positive correlation of IL-1 $\beta$ with CRP in second visit and positive correlation of IL- 6 with ESR in third visit, in the majority, cytokine levels did not correlated with CRP nor ESR. The cytokines and autoantibodies interplay in holistic pathophysiological model of RA development is suggested by positive correlations of serum cytokines after 6 months from diagnosis with anti-CCP and RF initial values. 


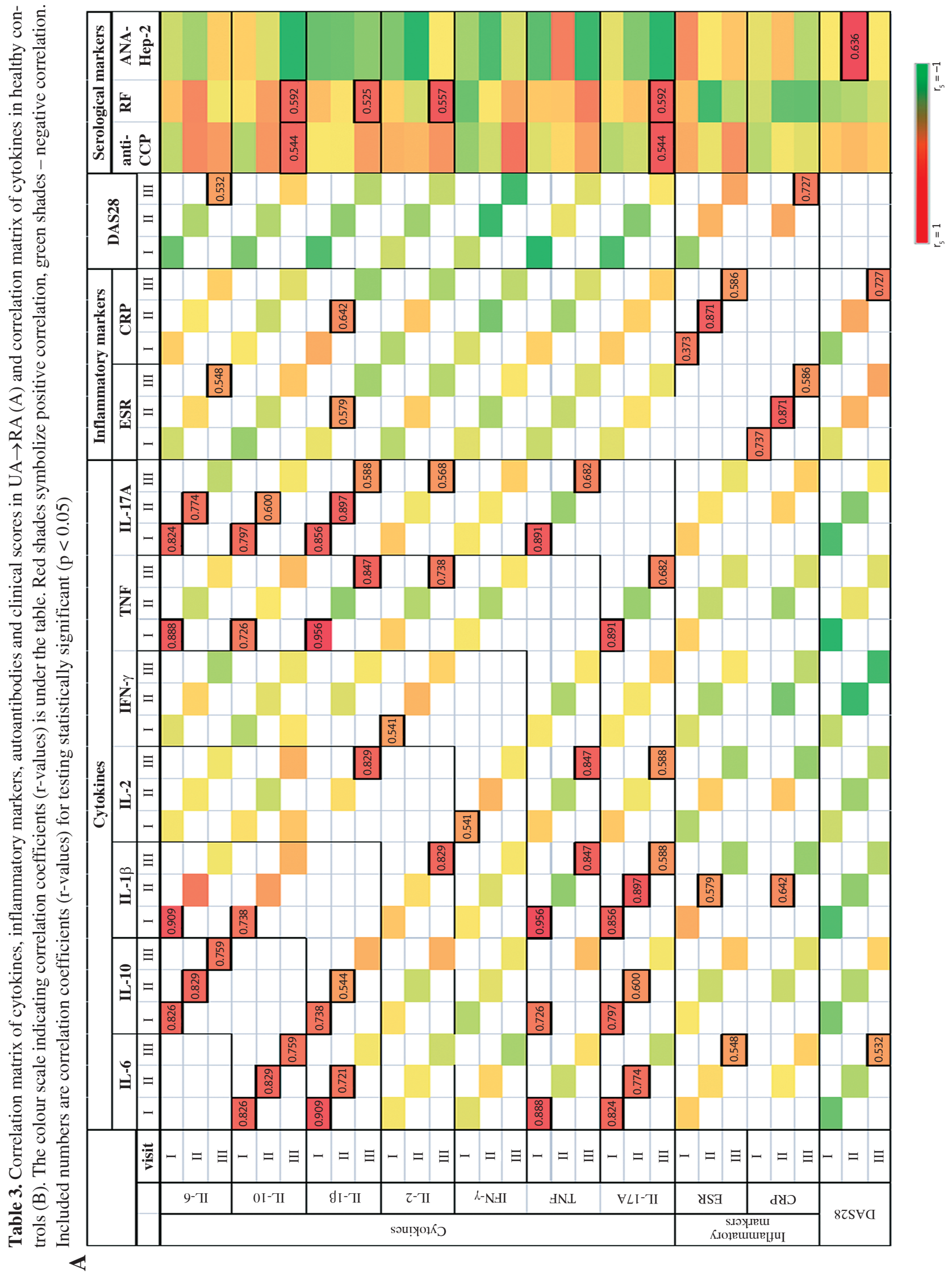


Table 3. Cont.

\begin{tabular}{|c|c|c|c|c|c|c|c|c|}
\hline & & \multicolumn{7}{|c|}{ Cytokines } \\
\hline & & IFN- $\gamma$ & IL-2 & IL-6 & IL-10 & IL-17A & IL-1 $\beta$ & TNF \\
\hline \multirow{7}{*}{ 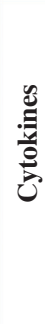 } & IFN- $\gamma$ & & & & & & 0.511765 & \\
\hline & IL-2 & & & & & & & \\
\hline & IL-6 & & & & 0.758824 & 0.752941 & 0.714706 & 0.685294 \\
\hline & IL-10 & & & 0.758824 & & 0.541176 & 0.673629 & 0.576471 \\
\hline & IL-17A & & & 0.752941 & 0.541176 & & 0.650000 & 0.579412 \\
\hline & IL-1b & 0.511765 & & 0.714706 & 0.673529 & 0.650000 & & 0.747059 \\
\hline & TNF & & & 0.685294 & 0.576471 & 0.579412 & 0.747059 & \\
\hline
\end{tabular}

This study was supported by Medical University of Gdansk grant MN 01-0139/08 to Edyta Brzustewicz. The funding source had no role in study design, collection, analysis, interpretation of data, writing of the report, or the decision to submit the report for publication.

The authors declare no conflict of interest.

\section{References}

1. Aletaha D, Neogi T, Silman AJ, et al. (2010): Rheumatoid arthritis classification criteria: an American College of Rheumatology/European League Against Rheumatism collaborative initiative. Arthritis Rheum 62: 2569-2581.

2. Shi LL, Chen P, Xun YP, et al. (2015): Prohibitin as a novel autoantigen in rheumatoid arthritis. Cent Eur J Immunol 40: 78-82.

3. van der Woude D, Toes RE, Scherer HU (2014): How undifferentiated arthritis evolves into chronic arthritis. Best Pract Res Clin Rheumatol 28: 551-564.

4. Wallace DJ, Gavin IM, Karpenko O, et al. (2015): Cytokine and chemokine profiles in fibromyalgia, rheumatoid arthritis and systemic lupus erythematosus: a potentially useful tool in differential diagnosis. Rheumatol Int 35: 991-996.

5. Curtis JR, van der Helm-van Mil AH, Knevel R, et al. (2012): Validation of a novel multibiomarker test to assess rheumatoid arthritis disease activity. Arthritis Care Res (Hoboken) 64: 1794-1803.

6. Miossec P, Verweij CL, Klareskog L, et al. (2011): Biomarkers and personalised medicine in rheumatoid arthritis: a proposal for interactions between academia, industry and regulatory bodies. Ann Rheum Dis 70: 1713-1718.

7. Smolen JS, Aletaha D, Grisar J, et al. (2008): The need for prognosticators in rheumatoid arthritis. Biological and clinical markers: where are we now? Arthritis Res Ther 10: 208.

8. Nielung L, Christensen R, Danneskiold-Samsře B, et al. (2015): Validity and Agreement between the 28-Joint Disease Activity Score Based on C-Reactive Protein and Erythrocyte Sedimentation Rate in Patients with Rheumatoid Arthritis. Arthritis 2015: 401690.

9. Leslie D, Lipsky P, Notkins AL (2001): Autoantibodies as predictors of disease. J Clin Invest 108: 1417-1422.

10. Deane KD (2014): Preclinical rheumatoid arthritis (autoantibodies): an updated review. Curr Rheumatol Rep 16: 419.
11. Yang Z, Ren Y, Liu D, et al. (2016): Prevalence of systemic autoimmune rheumatic diseases and clinical significance of ANA profile: data from a tertiary hospital in Shanghai, China. APMIS 124: 805-811.

12. Koszarny A, Majdan M, Suszek D, et al. (2013): Relationship between rheumatoid arthritis activity and antithyroid antibodies. Pol Arch Med Wewn 123: 394-400.

13. Burska A, Boissinot M, Ponchel F (2014): Cytokines as biomarkers in rheumatoid arthritis. Mediators Inflamm 2014: 545493.

14. Niu X, Chen G (2014): Clinical biomarkers and pathogenic-related cytokines in rheumatoid arthritis. J Immunol Res 2014: 698192.

15. Deane KD, O’Donnell CI, Hueber W, et al. (2010): The number of elevated cytokines and chemokines in preclinical seropositive rheumatoid arthritis predicts time to diagnosis in an age-dependent manner. Arthritis Rheum 62: 3161-3172.

16. Fransen J, van Riel PL (2006): DAS remission cut points. Clin Exp Rheumatol 24 (6 Suppl 43): S-29-32.

17. Verpoort KN, van Dongen H, Allaart CF, et al. (2004): Undifferentiated arthritis--disease course assessed in several inception cohorts. Clin Exp Rheumatol 22 (5 Suppl 35): S12-S17.

18. Krabben A, Abhishek A, Britsemmer K, et al. (2013): Risk of rheumatoid arthritis development in patients with unclassified arthritis according to the 2010 ACR/EULAR criteria for rheumatoid arthritis. Rheumatology (Oxford) 52: 1265-1270.

19. Lard LR, Visser H, Speyer I, et al. (2001): Early versus delayed treatment in patients with recent-onset rheumatoid arthritis: comparison of two cohorts who received different treatment strategies. Am J Med 111: 446-451.

20. Monti S, Montecucco C, Bugatti S, et al. (2015): Rheumatoid arthritis treatment: the earlier the better to prevent joint damage. RMD Open 1 (Suppl 1): e000057.

21. Kay J, Morgacheva O, Messing SP, et al. (2014): Clinical disease activity and acute phase reactant levels are discordant among patients with active rheumatoid arthritis: acute phase reactant levels contribute separately to predicting outcome at one year. Arthritis Res Ther 16: R40.

22. Brzustewicz E, Bryl E (2015): The role of cytokines in the pathogenesis of rheumatoid arthritis - practical and potential application of cytokines as biomarkers and targets of personalized therapy. Cytokine 76: 527-536.

23. Shrivastava AK, Singh HV, Raizada A, Singh SK, Pandey A, Singh N, et al. Inflammatory markers in patients with rheumatoid arthritis. Allergol Immunopathol (Madr) 2015; 43: 81-7. 
24. Vittecoq O, Pouplin S, Krzanowska K, et al. (2003): Rheumatoid factor is the strongest predictor of radiological progression of rheumatoid arthritis in a three-year prospective study in community-recruited patients. Rheumatology (Oxford) 42: 939-946.

25. Rantapää-Dahlqvist S, de Jong BA, Berglin E, et al. (2003): Antibodies against cyclic citrullinated peptide and IgA rheumatoid factor predict the development of rheumatoid arthritis. Arthritis Rheum 48 (10): 2741-2749.

26. Nakamura H, Usa T, Motomura M, et al. (2008): Prevalence of interrelated autoantibodies in thyroid diseases and autoimmune disorders. J Endocrinol Invest 31: 861-865.

27. Mariz HA, Sato EI, Barbosa SH, et al. (2011): Pattern on the antinuclear antibody-HEp-2 test is a critical parameter for discriminating antinuclear antibody-positive healthy individuals and patients with autoimmune rheumatic diseases. Arthritis Rheum 63: 191-200.

28. Ally MM, Hodkinson B, Meyer PW, et al. (2015): Circulating anti-citrullinated peptide antibodies, cytokines and genotype as biomarkers of response to disease-modifying antirheumatic drug therapy in early rheumatoid arthritis. BMC Musculoskelet Disord 16: 130 .

29. Bienvenu J, Monneret G, Fabien N, et al. (2000): The clinical usefulness of the measurement of cytokines. Clin Chem Lab Med 38: 267-285.

30. Uno K, Yoshizaki K, Iwahashi M, et al. (2015): Pretreatment Prediction of Individual Rheumatoid Arthritis Patients' Response to Anti-Cytokine Therapy Using Serum Cytokine/ Chemokine/Soluble Receptor Biomarkers. PLoS One 10 (7): e0132055.

31. Davis J (2009): Cytokine biomarkers and the promise of personalized therapy in rheumatoid arthritis. In: Matteson E, editor. Rochester, Minnesote: Reumatologia Clinica 143-146.

32. Brennan FM, McInnes IB (2008): Evidence that cytokines play a role in rheumatoid arthritis. J Clin Invest 118: 3537 3545.

33. Alex P, Szodoray P, Knowlton N, et al. (2007): Multiplex serum cytokine monitoring as a prognostic tool in rheumatoid arthritis. Clin Exp Rheumatol 25: 584-592. 